\title{
The Future of Indigenous Languages: Challenges of Translating Mavilan Songs
}

LILLYKUTTY ABRAHAM

\begin{abstract}
This paper attempts to look at the challenges and problems faced while translating the oral songs of Mavilan tribe into English. Mavilan community, an indigenous group, settled in Kannur and Kasaragod districts of Kerala has unique oral songs that reveal their way of life. These oral songs replete with cultural references are loaded with specific meaning to the tribe. These songs are a cultural tool to study about the tribe. In order to disseminate their rich cultural heritage it is necessary to translate their language. However while translating the songs into English, it is found insufficient to convey the rich cultural meaning intended. Against this backdrop through the analysis of the select oral songs of the tribe, this paper delves into some of the challenges faced during the translation and proposes some possible solutions that might augment the preservation and dissemination of their language.
\end{abstract}

Keywords: Indigenous Language, Mavilan Tribe, Oral Songs, Translation, Culture.

\section{Introduction}

Indigenous languages are unique and loaded with rich cultural implications. These languages manifest the indigenous people's life as holistic and continuous in a cyclic way of existence. Mavilan tribe settled in Kannur and Kasaragod districts of Kerala has a unique language that indicates their specific way of life. In addition to their usual modes of exchange of ideas, their language can be identified in their oral tales and songs, proverbs, riddles and rituals. While trying to understand these utterances and to disseminate them through 
translation, English language is found inadequate to convey the meaning intended. Hence, in this paper, an attempt is made to delve into some of the issues encountered while translating their utterances particularly their oral songs into English.

\section{Methodology}

The songs were collected during the fieldwork in Mavilan hamlets in Kannur and Kasaragod districts ranging from the year 2013 to 2017 as part of research work for the author's $\mathrm{Ph} . \mathrm{D}$. in ecocriticism. The songs were videotaped during the oral recitation by the informants. These songs were transcribed and doubtful words were clarified with the help of experts. Interviews and discussions were held to study the songs in detail.

\section{Mavilan Tribe}

The people of Mavilan tribe mostly inhabit Kannur and Kasaragod districts of North Kerala. They are a minority group. According to the census of the year 2011, their total population was 30,867 of whom 14,972 were males and 15,895 females. Mavilan tribe was once hunter-gatherers who relied solely on forest produce and wild life for their sustenance. During the course of time, when the landlords encroached their habitats they had to leave their traditional way of life and eventually they became agricultural labourers.

\section{Language of the Tribe}

The language the tribe spoke in the past was Tulu. However, currently Tulu is spoken only in their hamlets in Kasaragod region. They have their own colloquial language which is rhythmic and musical and similar to Malayalam. In both Kannur and Kasaragod regions Malayalam is the common medium to communicate with outsiders. The transcribed text employed in this paper is translated from Malayalam to English by the author. 


\section{Significance of Songs as a Cultural Tool}

Songs were integral to the rhythmic and ceremonial way of life of Mavilan community. Their life was interwoven with oral songs. They had songs for every occasion in which they came together as a community and they celebrated life by singing and playing thudi, their musical instrument. These songs had many functions in the collective life of the tribe in the past. For instance, songs functioned as an expression of collective memory, a medium to preserve customs and traditions, a means of transmitting cultural values, a medium of catharsis in their oppressive context of being the agricultural labourers of the landlord, a mirror of the socio economic reality, satire of the oppressive social set up and protest against the caste system. Since the oral songs of the tribe play a vital role in any attempt to study the tribe, faithful translation of these songs are of paramount importance.

\section{Challenges Faced while Translating the Songs}

The signified is loaded with cultural implications for the indigenous community as the utterances reflect their lived experience of their holistic worldview. Therefore, what a term signifies in the source language calls for an understanding of the culture of the community when it is translated to the target language. As Susan Bassnett and Harish Trivedi point out, "translation does not happen in a vacuum, but in a continuum; it is not an isolated act, it is part of an ongoing process of intercultural transfer" (1999: 2). In the indigenous context, it is true that "the act of translation always involves much more than language. Translations are always embedded in cultural and political systems and in history" (6). In the case of Mavilan tribe too, the songs cannot be treated in isolation as they came into being in their particular history. Therefore, they have to be viewed in the context of the social reality of the time. 
Mavilan community experiences life as a continuous flow, a continuum of relations with the ancestors, the present generations and the generations yet to be born. Hence, while translating the songs, the culture of the tribe plays a vital role. Nevertheless, these songs were not composed for any audience. They emerged from the direct experience of the tribe especially in the context of the oppression they had to endure under the landlord. In this context, these songs evolved as part of their cultural existence and as a means of survival. In other words, these songs were the self-expression of the collective existence of the community. However, since these songs are a cultural tool to be familiarised with the history and the culture of the tribe, they need to be translated for a wider audience. A non-Mavilan endeavour to translate their songs is possible only from the information received from the informants. It is not the same experience as that of the first speakers in the particular context. The challenge is how far that experiential knowledge of the community can be translated at the experiential level that the community had intended. Even by employing the paratextual commentary, can the reader be led to such an experiential level? A reader of the translated work gets to know only what is translated. Therefore, the role of the translator in the indigenous context is more challenging than that of other languages. Vladimir Ivir claims that translation means translating cultures and not languages (1987: 35). If so, how far can an indigenous culture be truly translated in the context of the Mavilan community? Can the translated text adequately unravel the intricacies of their rich culture?

The fidelity of the translated text to the source text must be taken into consideration in this context. Maria Tymoczko observes, "The translator is faced with the dilemma of faithfulness...in obscuring or muting the cultural disjunctions, the translator ceases to be "faithful' to the source text" (1999: 21). A. K. Ramanujan offers another approach in such 
situations. He postulates, "A translator hopes not only to translate a text, but hopes (against all odds) to translate a nonnative reader into a native one. The Notes and Afterword are part of that effort" (1978: viii). Even in such attempts, can a non-native reader be fully translocated to the native? It must be admitted that it is not likely. Hence, a translator attempts to make the meaning as close as possible. Just as Ganesh Devi points out, "Translation can be seen as an attempt to bring a given language system in its entirety as close as possible to the areas of significance that it shares with another given language or languages. All translations operate within this shared area of significance" (1999: 186). The oral songs of Mavilan community must be viewed against this backdrop.

Mavilan community maintains a well-knit kinship. They followed matrilineal system of inheritance in the past. A person is closely associated with the son or daughter of his or her mother's brother or brothers in this socio cultural set up. The term that denotes this relationship for a boy is machunan and for a girl is machunachi. This relationship can even lead to marriage. In such cases, the prefix ner added to these terms denotes the specific relation between the two cousins. The children of the tribe grow up in such a custom and they maintain a very close relationship between the two. The term ner machunan occurs in the following lines of "Adichuthalippattu," one of the nuptial songs of the tribe recorded from Umpichi Kanathumoola of Banam in Kasaragod district:

Eni penne eni penne Neeliyottu Makke. Mooli murandonduRangunnoru pennu. Koottathilundu polum Ner machuniyanmaru,
Get up, girl; get up, girl, Neeliyottu Makke. Grunting and snoring Sleeps the girl. There among them is The direct cousin, 


\section{Adiyennu mudiyolam $\quad$ From bottom to top Thappiyunarthunnu Groping, wakes her up.}

In order to understand the action of groping by the cousin, the cultural background of the tribe especially their kinship relationship must be known to the reader. Therefore, the translator needs to add footnotes to describe the term ner machunan. 'Cousin' is the only word in English to signify the relationship between a person's uncle's son or daughter and himself or herself. Cousin denotes both genders. Therefore, when the term 'cousin' substitutes machunan it has to be specified that it is a male. Ner machunan also means that though there are many cousins of direct relations as first cousins, the person mentioned is a sort of fiancé or her future husband. He is the son of her mother's brother and not any other cousins. Unless the term is not clarified the meaning of this wedding song remains ambiguous.

The song "Chonodum Kannan" sung by P. M. Karichi of Kolangara settlement of West Elery panchayat in Kasaragod district has the description of different rites of passage the eponymous hero undergoes. If the term 'enangan' used in the song has to be understood well, the reader needs to know the customs and traditions of the tribe. Mavilan tribe followed the custom of a few ex officio members administering and assisting at their different rites of passage. These members known as enangan (male) or enangathi (female) are not kin but are closely related as same family members. A nonMavilan would find it hard to relate to the specific nature of this 'kinship.' Hence, even a footnote would not suffice to describe the cultural meaning implied. The following is an excerpt of the song:

Ezhu vayathunni

Thirikkathu kuthanam.

Tirikkathu kuthanaru?
At the age of seven

Ears are to be pierced.

Who is to pierce the ears? 
The Future of Indigenous Languages: ...

Oreerenangamaru.

Kayalin kana kothi

Mullum cheranti.

Kaathinu mullanakkunnu

Reerenangamaru.
Two enangan each.

Cutting a twig of bamboo

shaped into a thorn.

Pierce the earlobes

Both the enangan.

A reader cannot relate to the meaning of terms without the background knowledge of the agricultural slavery and exploitation the tribe endured. Orakkuzhi where the paddy was pounded or de-husked was an outhouse in the household of a landlord. The existence of such spaces has to be looked at from the perspective of the sociocultural context of the agricultural slavery of the past. Although the landlord strictly observed untouchability and unapproachability, the lower caste women were allowed to enter this area. Mavilan tribe that experienced harsh treatment and sexual exploitation could not but vent their emotions through the medium of songs. While translating such songs, mere explanation of the term orakkuzhi does not suffice to transmit the cultural meaning and experience implied. An excerpt of the song sung by Kakkoppuram Kunhiraman from Payyavoor panchayat of Kannur District is given below:

Аа...оо...ее...ии..

Onnu parayathundu

Kaithari Nambyar.

Karincholakkanni pennu

orakkuzheelu Varanam.

Onnundu kelkku nambyare

Kaithari Nambyar,

Aa...oo...eе...uu...

Thodalum theendalum

Ningakkille nambyare?

Pinnengana nambyare

Nhanaduthu varunnu?
Aa...oo...ee...uu..

Thus says

Kaithari Nambyar.

Karincholakkanni girl

Must come to the orakkuzhi.

Please listen, Nambyar

Kaithari Nambyar, Aa...oo...eе...uи...

Untouchability and unapproachability

Don't you, Nambyar, observe?

How can then, Nambyar

I come near to you? 
'Nhakkalu kathi' refers to the knife used only for cutting the umbilical cord. While translating the song "Chappa" sung by Kanathumoola the term needs to be explained. However, the term is loaded with the cultural practice of the past when the delivery took place at home itself. Unless the tribe's socio cultural life of the past is not known, the reader may be perplexed. An excerpt of the song is given below:

Pennungale -

Pennungale -

Kutti-Thalu-

Pettu-

Ngyavoo- Ngyavoo-

Ey-pennungale -

Nikku- nikku-

Vaymaranhu- nikku-

Vaymaranhu- nikku-

Pokka-Netta-

Pokkalu-

Murikkunna-

Nhakkalu - kathi-

Kondu-vay-
Women,

Women,

Kutti, Thalu.

Delivered

Ngyavoo- Ngyavoo

Ey, Women,

Stop, stop

Turn back and stop,

Turn back and stop.

Pokka, Netta,

Umbilical cord

For cutting

Nhakkalu knife

Bring.

In the past, when a large quantity of paddy had to be dehusked, it was not pound inside the mortar; instead, it was pounded on the floor. The term 'nilakkuthu' denotes this cultural practice. Therefore, though in the following excerpt sung by Kunhiraman, the term is translated, it calls for a detailed description:

Iniyenthu paniyenthu

Tharamenthu amme?

Innale onanginoru

Nellathu kutheela

Kuthumpam kuthunnu pennu Nilakkuthu kuthunnu
What is the next work

To be completed, mother?

(The paddy that) dried yesterday, That paddy is not de-husked

While pounding, pounds, the girl Pounds on the floor. 
Ecological knowledge is another challenge faced while translating the songs of the tribe. The term 'kooran' is used in the oral song of hunting, recorded from Karichi. While the animal is extinct, it is difficult to identify the animal referred to. Resorting to NBS Malayalam English Dictionary by C. Madhavan Pillai, the term is identified as "the abrus plant; a species of deer; (hog-deer); dog; a dwarf" (283). Kerala Bhasha Nighantu also defines the term as "a kind of pig, a small animal in the species of deer, small musk deer, dog, dwarf, a type of paddy, wild hare, kooran grass" (609). The informants are of the view that it is like a wild hare sans large ears and is similar to the mongoose. Therefore, while translating the song into English, the translator is perplexed as to which word can be used for the exact meaning of the term. Employing the para-textual commentary seems a fairly faithful way of translating the word kooran to English.

The measuring units the tribe used in the past, recurs in the songs signifying the culture of barter of the paddy cultivation. When nazhi is translated as a 'measuring unit of old equivalent to approximately 200 grams' as footnote, can the reader relate to such a culture? In the following lines of the song "Purli," sung by Karichi, nazhi represents the unequal wages the tribe received for their tireless hard labour in the field of the landlord:

Moonnadam Moorunnittu Purli Having harvested for three days, O Purli,
Monnazhi nellu kitti
(We) received three nazhi paddi.

The text above cannot be understood with all its implications unless the reader can relate to the agricultural slavery of the past. Therefore, there arises the need to introduce the reader to some basic knowledge of their socio cultural life of the past. 
Considering the specific nature of the language of Mavilan tribe in particular and the indigenous languages in general, the challenge is the survival of these languages. In the context of global culture how much of the regional will be safeguarded? Since the quickly progressing world tends to promote a few dominant languages, the question remains a challenge. As Andrew Dalby had already foreseen, "A time will certainly come when English, French, Spanish and the other national languages of the world somewhere around two hundred in total are the only languages still in use, each dominant within its own borders" (2003: 277). He proposes that this time "will be reached in less than two hundred years from now" (279) and adds, "By then it will be easy to foresee the speed with which the last milestone will be attained, the point at which only English is spoken. It is closer than you think. And no more bilingualism then" (280). It is appalling to realize that in India too, the scenario is not very different. In such a context, where will the place of indigenous languages and culture be?

\section{Possible Solutions}

In this frightening scenario, despite the challenges, the endangered languages need to be promoted to keep them alive along with the culture of the community. Hence, it is vital that the art forms of the indigenous groups be recorded and disseminated to other cultures as well. The art forms like the oral songs, dance, proverbs, sayings, and their medicinal knowledge can contribute to the mainstream community and enhance life in general. It is the responsibility of the mainstream community who has the technology and the knowhow of the ways of preservation, to encourage the indigenous communities to maintain their language. It calls for mutual give and take from both the communities. They need to be approached with openness and respect and not with an attitude of superiority of 'saviours;' instead, the mainstream 
community can learn many superior ways from them. This can effectively reduce the distancing of the 'other.' It is important to realize and recognize the contribution the indigenous communities can make for the well-being of the cosmos. Efforts have to be taken to translate the indigenous languages to other regional and national languages and make them available to a greater audience.

\section{Conclusion}

To summarise, an attempt is made in this paper to look at the challenges faced in translating into English the oral songs of Mavilan tribe. It is clear from the discussion that the language of the indigenous community cannot be translated fully unless the cultural implications too are not made clear. For an indigenous community, particularly for Mavilan community, language is part of their holistic way of life and hence cannot be isolated from the culture. In a translated work of their utterances how much of their culture too can be transferred is still a question not answered fully. Therefore, will these languages remain alive in the long run? Can indigenous languages survive in a global culture? These alarming questions call for responsible response from the intelligentsia.

\section{References}

Anantha Murthy, U. R. 1978. Samskara. Translated by A. K. Ramanujan. New York: Oxford University Press.

BASSNETT, SUSAN \& HARISH TRIVEDI. 1999. Introduction: Of Colonies, Cannibals and Vernaculars. In Susan Bassnett \& Harish Trivedi (eds.), Post-colonial Translation: Theory and Practice. 1-18. London: Routledge.

DALBY, ANDREW. 2003. Language in Danger: The Loss of Linguistic Diversity and the Threat to Our Future. New York: Columbia University Press. 
Devi, Ganesh. 1999. Translation and Literary History -an Indian View. In Susan Bassnett \& Harish Trivedi (eds.), Post-colonial Translation: Theory and Practice. 182-188. London: Routledge.

IVIR, Vladimir. 1987. Procedures and Strategies for the Translation of Culture. Indian Journal of Applied Linguistics, (13)2. 35-46.

KanthumoOla, U. (2015, November 11). Personal Interview by Lillykutty Abraham. Unpublished.

KARICHI, P. M. (2016, April 7). Personal Interview by Lillykutty Abraham. Unpublished.

Thampan, M. 1997. Kerala Bhasha Nighantu. Thiruvananthapuram: SIL.

Kunhiraman, K. (2016, July 17). Personal Interview by Lillykutty Abraham. Unpublished.

MadHaVan PILlaI, C. 1999/1976. NBS Malayalam English Dictionary. Kottayam: Sahitya Pravarthaka Co-operative Soc. Ltd.

Ramanujan, A. K. 1978. Translator's Note. In U.R. Anantha Murthy, Samskara: A Rite for a Dead Man. viii. New York: Oxford University Press.

TYMOCZKO, MARIA. 1999. Post-colonial Writing and Literary Translation. In Susan Bassnett \& Harish Trivedi (eds.), Post-colonial Translation: Theory and Practice. 19-41. London: Routledge.

$$
* * *
$$

\section{Cite this Work:}

ABRAHAM, LiLlykUtTy. 2020. The Future of Indigenous Languages: Challenges of Translating Mavilan Songs. Translation Today, Vol. 14(2). 107-118. DOI:10.46623/tt/2020.14.2.ar6 